\title{
Risk assessment methodology for iron stability under water quality factors based on fuzzy comprehensive evaluation
}

\author{
Jiaying Wang ${ }^{1}$, Hexiang Yan ${ }^{1}$, Kunlun Xin ${ }^{1,2}$ and Tao Tao ${ }^{1,2^{*}}$ (]
}

\begin{abstract}
Background: Changing water quality was prevalent in the current water supply. The fluctuation of iron stability due to changing water quality followed four characteristics: objectivity, relativity, predictability, and controllability. Therefore, it was necessary to study the stability of iron in the pipe network by integrating different water quality factors.

Results: The iron stability risk evaluation system was established according to the different water quality factors in the drinking water distribution systems (DWDSs). Meanwhile, an improved fuzzy comprehensive evaluation method was established to evaluate the risk of iron. Chloride, sulfate, dissolved organic matter (DOM) and pH were selected as the risk assessment index. The divisions of different evaluation levels were carried out through the values of water quality factor. On the basis of expert scoring, the weight and membership degree of water quality factors were analyzed by structural entropy method. In addition, risk analysis was established by using the optimized risk assessment system. According to the results of the comprehensive evaluation, DOM and pH were identified as two of the most important factors in the evaluation of the iron stability. In addition, compared with the traditional fuzzy comprehensive evaluation method, the optimized method had a higher degree of fit which could more clearly prove the relationship between the risk value and the iron concentration.
\end{abstract}

Conclusion: The uncertainty between the factors was eliminated by establishment of the fuzzy evaluation method combined with the different effects of water factors on iron stability. The method could be used as a comprehensive evaluation and be beneficial to the analysis of iron risk in water supply network.

Keywords: Risk assessment, Iron stability, Water quality factors, Fuzzy comprehensive evaluation

\section{Background}

Iron was often found in the water supply pipe network which could cause unpleasant metallic taste, water fouling and rusty color [1]. In the past few years, iron problems in the drinking water distribution systems (DWDSs) have attracted extensive attentions [2,3]. Water supply pipes generally consist of metal pipes, plastic pipes and other types of pipes, meanwhile, metal pipes are the main ones [4]. However, the inner coating in metal pipes

\footnotetext{
*Correspondence: taotao@tongji.edu.cn

${ }^{1}$ College of Environmental Science and Engineering, Tongji University,

Shanghai 200092, China

Full list of author information is available at the end of the article
}

gradually failed and flaked off for a long-time use, the pipe would be largely corrupted. The risk of iron stability was based on the changing of water quality conditions.

The fluctuation of iron stability produced by changing water quality followed the four characteristics: objectivity, relativity, predictability, and controllability. Objectivity referred to the phenomenon of the iron stability posed by different water quality conditions based on objective facts. Relativity was mainly due to the lag of the water quality information and the degree of accurate grasp on the mechanism of iron stability. Predictability meant the changes of iron stability could be predicted by the study of water quality in the pipe network. Controllability could be considered as the controlling of iron risk. 
Previous studies demonstrated that goethite $(\alpha-\mathrm{FeOOH})$, lepidocrocite $(\gamma-\mathrm{FeOOH})$, and magnetite $\left(\mathrm{Fe}_{3} \mathrm{O}_{4}\right)$ are the main elements contained in iron scales on the inner walls of drinking pipes $[5,6]$. The stability of iron in the DWDSs was affected by a variety of factors, especially the water quality factors including chloride, sulfate, dissolved organic matter (DOM), $\mathrm{pH}$ and so on. Each water quality factor showed different effect on iron stability. Chloride and sulfate were deemed to destroy the stability of iron in the DWDSs, increasing iron concentration in water $[7,8]$. DOM played a key role in iron stability which was recorded to reduce ferric iron colloids to soluble ferrous iron $[9,10]$. And the increasing of $\mathrm{pH}$ was demonstrated to enhance the iron stability and decrease the iron releasing in actual distribution systems [11].

At present, it is difficult to fully assess the iron pollution in the DWDSs for the limited number of detection points and the expensive costing. A method needs to be established to evaluate the stability of iron through conventional water quality parameters. Therefore, based on mathematical analysis, the evaluation method was established to evaluate the impact on iron pollution under different water quality conditions in the DWDSs. This research mainly focused on the four factors (chloride, sulfate, DOM and $\mathrm{pH}$ ). The comprehensive risk assessment method should combine qualitative indexes and quantitative indexes. It was difficult to carry out an accurate quantitative analysis of the evaluation results for the ambiguous effect of different water quality conditions on iron stability. In addition, the relationships between the different water qualities factors were not clear which led to ambiguity in the set and calculation of indicators. Therefore, in view of the 'fuzzy' characteristics of the evaluation indexes, the fuzzy comprehensive evaluation method was used to evaluate the iron stability.

The fuzzy comprehensive evaluation method was a mathematical method which was proposed to evaluate and solve the problem with fuzziness of constrained boundary condition and unclear concepts [12-14]. The concept of fuzzy sets depicting imprecision and vagueness was introduced by Zadeh who defined the fuzzy mathematical theory in 1965 for the first time. The concrete analysis method of quantitative fuzzy problem made up the deficiency that classical mathematics could not quantify and analyze fuzzy things accurately. Fuzzy comprehensive evaluation was used to deal with the quantitative factors which were difficult to quantify based on the fuzzy mathematics as the theoretical basis, such as water resources carrying capacity [15] and water quality risk assessment [16]. There were no clear boundaries between the conceptual nature and the specificity of the iron stability in the DWDSs. The fuzzy comprehensive evaluation and analysis method could be used to analyze the iron risk assessment under different water quality conditions. However, in the previous process of calculating membership, the comprehensive evaluation would be uncertain under the case index of the membership degree is less than or greater than the minimum or maximum median. Therefore, this research considered to optimize this part and establish an optimized fuzzy method.

\section{Methods}

The results of the environmental risk assessment were not absolute [17], but the risk assessment of iron stability in this study was relative. The changing between the different water quality factors and the same water quality factors in different values had different effects on the iron stability. Thence, the evaluation variables were ambiguous and difficult to synthesize the accurate prediction results. However, the fuzzy evaluation method used the weighting principle to take full account of the factors. Different factors were evaluated through the subjective and objective steps, resulting in reducing the uncertainty of the variables. Finally, the corresponding risk of iron stability on the comprehensive evaluation results was obtained.

There were multiple uncertainties in the DWDSs. The water quality factors had fuzzy characteristic. Therefore, in order to deal with the problem on iron stability, this research developed a model by integrating analytic hierarchy process (AHP) method and fuzzy sets into risk assessment model. The model could be described as following: (1) establishing the evaluation object and the evaluation indexes; (2) analyzing the improved fuzzy evaluation system; (3) getting the weights of the comparison elements and the risk level to obtain the risk assessment value. The detailed solution process is explained as follows.

\section{Establishing the evaluation system}

The need to determine the evaluation objective and evaluation objects was the primary assignment of establishing an evaluation system. This research focused on the impact of the four water quality factors (chloride, sulfate, DOM and $\mathrm{pH})$ on iron stability in the DWDSs. The evaluating index set $U=\left\{u_{1}, u_{2}, u_{3} \ldots u_{n}\right\}$ for the iron stability was established, $u_{1}-u_{n}$ represented as the evaluating index. All of the four types of water quality parameters were quantitative indicators.

$$
U=\left\{u_{\mathrm{Cl}}^{-}, u_{\mathrm{SO}_{4}^{2-}}, u_{\mathrm{DOM}}, u_{\mathrm{pH}}\right\} .
$$

\section{Evaluating index weight method}

In order to reflect the impacts of water quality factors on iron stability, the different weights of water quality factors were settled. The weighting method used in this section was the structural entropy method. 
The entropy method was based on the subjective basis of the indicators' importance on the evaluation object [18]. It was used to analyze by the entropy and the blind analysis. Finally, the weight of the index was obtained by normalization $[19,20]$.

\section{Expert order}

The assessments in this section provided researchers in the field of environmental to get the scoring table according to the individual's understanding and experience of the evaluation index. The importance of the four water quality factors (chloride, sulfate, DOM and $\mathrm{pH}$ ) was analyzed.

In this section of the analysis, experts were invited to participate in the questionnaire. Each row represented the importance of the same expert for the importance of the indexes, and each column indicated the importance of different experts to the same indicator in the index matrix formula (2):

$$
A=\left(\begin{array}{ccc}
\mathrm{a}_{11} & \cdots & \mathrm{a}_{1 \mathrm{n}} \\
\vdots & \ddots & \vdots \\
\mathrm{a}_{\mathrm{n} 1} & \cdots & \mathrm{a}_{\mathrm{nn}}
\end{array}\right) .
$$

\section{Blind analysis}

Blind analysis was used in order to eliminate the phenomenon of uncertainty which might be generated by the experts in the sorting process due to personal subjective reasons. Membership function could be transformed from the 'expert order' which established as:

$$
\chi(I)=-\lambda p_{n}(I) \ln p_{n}(I) .
$$

$I$ was the index of the indicator by experts, $I=1,2, \ldots, j$ according to the importance of the indicator; $m=j+2, p_{n}$ and $\lambda$ were the functions formed by $m$ :

$$
\begin{aligned}
& p_{n}(I)=\frac{m-I}{m-1}, \\
& \lambda=\frac{1}{\ln (m-1)} .
\end{aligned}
$$

Therefore, the membership function $\mu(I)$ could be established as:

$$
\begin{aligned}
& \chi(I) /\left(\frac{m-I}{m-1}\right)=-\frac{\ln (m-I)}{\ln (m-1)}+1, \\
& \mu(I)=\frac{\ln (m-I)}{\ln (m-1)} \in[0,1] .
\end{aligned}
$$

In addition, the overall degree of $x_{j}$ of the experts on the indicator $u_{j}$ could be expressed as:

$$
x_{j}=b_{j}\left(1-\sigma_{j}\right) \text {, }
$$

in which $b_{j}$ was defined as the same scoring of indexes by the total $k$ experts, $b_{j}=\left(b_{1 j}+b_{2 j}+\cdots+b_{k j}\right) / k, \sigma_{j}$ was the uncertainty of the indicators impacting on the evaluation object, $\sigma_{j}=\left\lfloor\left\{\left[\max \left(b_{1 j}, b_{2 j}, \ldots, b_{k j}\right)-b_{j}\right]+\right.\right.$ $\left.\left[\min \left(b_{1 j}, b_{2 j}, \ldots, b_{k j}\right)-b_{j}\right]\right\} / 2 \mid, b_{k j}$ could be calculated by $\mu(I)$, and $k$ represented the number of the experts.

\section{Normalization of weight vector}

The weight needed to be normalized in the fuzzy comprehensive evaluation method in order to evaluate clearly. Normalize the degree of awareness $a_{j}$ as following in this research. Therefore, the weight vector of different water quality indicators could be obtained by normalization.

$$
\alpha_{j}=x_{j} / \sum_{j=1}^{k} x_{j}
$$

Therefore, formula (10) showed the weight vector of the evaluation objectives which could be calculated after the process of expert order, blind analysis, and normalization:

$$
W=\left\{W_{\mathrm{Cl}^{-}}, W_{\mathrm{SO}_{4}^{2-}}, W_{\mathrm{DOM}}, W_{\mathrm{pH}}\right\}
$$

\section{Evaluation grade $(V)$}

The evaluation grade referred to the classification of the evaluation object (iron stability) according to the impact of the evaluation objectives (water quality factors). The quantitative description of the four evaluation indexes (chloride, sulfate, DOM and $\mathrm{pH}$ ) were described according to the actual situation of each evaluation index. The evaluation of the situation was divided into five grades (slight risks, small risks, general risks, greater risks, significant risks), which were commonly used in fuzzy comprehensive evaluation. The evaluating grade set $V=\left\{v_{1}\right.$, $\left.v_{2}, v_{3}, v_{4}, v_{5}\right\}$ was established, $v_{1}-v_{5}$ represented as the five grades of the evaluation which depended on water quality factors. The evaluation grade of the iron risk assessment system was shown as the following:

$$
V=\left\{v_{\mathrm{slr}}, v_{\mathrm{smr}}, v_{\mathrm{ger}}, v_{\mathrm{grr}}, v_{\mathrm{sir}}\right\} .
$$

\section{Degree of membership function $\left(V_{n}\right)$}

Each evaluation factor had different influence on the evaluation result. Therefore, the membership degree of each evaluation factor corresponding to different evaluation grade was determined by setting membership 
function, according to the characteristics of the evaluation factors.

Water quality factors were divided into incremental factors and descending factors according to the influence on iron stability. Incremental factor and descending factor represented the risk increased with the value of the factor increasing or decreasing. According to the previous researches [7-10], the increasing concentration of chloride, sulfate and DOM in pipeline water would lead to an increasing risk of iron, while increased $\mathrm{pH}$ would led to decrease the risk [11]. The degrees of membership functions are shown in Table 1.

The risk of the iron stability under the different water conditions could be calculated synthetically based on the membership value and the weight of the four water quality factors shown in formula (12):

$$
\begin{aligned}
& R_{n}=W_{n} \times V_{n} . \\
& V_{\mathrm{Cl}^{-}}=\left\{v_{\mathrm{slr}}, v_{\mathrm{smr}}, v_{\mathrm{ger}}, v_{\mathrm{grr}}, v_{\mathrm{sir}}\right\}=\{(0,50),(50,100),(100,150),(150,200),(200,250)\}, \\
& V_{\mathrm{SO}_{4}^{2-}}=\left\{v_{\mathrm{slr}}, v_{\mathrm{smr}}, v_{\mathrm{ger}}, v_{\mathrm{grr}}, v_{\mathrm{sir}}\right\}=\{(0,50),(50,100),(100,150),(150,200),(200,250)\}, \\
& V_{\mathrm{DOC}}=\left\{v_{\mathrm{slr}}, v_{\mathrm{smr}}, v_{\mathrm{ger}}, v_{\mathrm{grr}}, v_{\mathrm{sir}}\right\}=\{(0,4),(4,8),(8,12),(12,16),(16,20)\}, \\
& V_{\mathrm{pH}}=\left\{v_{\mathrm{slr}}, v_{\mathrm{smr}}, v_{\mathrm{ger}}, v_{\mathrm{grr}}, v_{\mathrm{sir}}\right\}=\{(8.0,8.5),(7.5,8.0),(7.0,7.5),(6.5,7.0),(6.0,6.5)\} .
\end{aligned}
$$

\section{Index classification}

Sulfate and chloride were the indication of iron shape variation leading to the high concentration of red water [7]. DOM plays a key role in iron stability, could form complicated complexes with iron, meanwhile, the phenomenon of reducing ferric iron colloids to soluble ferrous iron was also recorded $[9,10]$. And $\mathrm{pH}$ was demonstrated to increase the iron stability in actual distribution systems [21]. Therefore, the numerical interval division of the four indictors on evaluation grade could be expressed as following. Formula (14)-(17) showed the corresponding grade for each water quality factors. Chloride, sulfate, dissolved organic carbon (DOC) (characterize DOM content) were the incremental factors, and $\mathrm{pH}$ was the descending factor:

\section{The optimized model with value outside the range} In the traditional method, both the values under the condition of smaller than the middle of the minimum range and bigger than the middle of the maximum range were ' 1 '. In order to distinguish the situation, the following calculating formulas were used to analyze the condition outside the range. $W$ represented the weight vector of the considered water factor which is out of the evaluation grade (Table 2):

$$
R_{n}^{\prime}=W_{n} \times V_{n} \times \Sigma_{n}\left(1+Q_{i} \times W_{i}\right) .
$$

\section{Variable fuzzy evaluation model for iron stability}

The four indictors (chloride, sulfate, DOM and $\mathrm{pH}$ ) were figured in this research, all of which were quantitative parameters and could affect the iron stability in the DWDSs.

\section{The experts order}

Table 3 shows the sorting of the four water quality factors (chloride, sulfate, DOM and $\mathrm{pH}$ ). Table 3 is calculated by using the fuzzy comprehensive evaluation method according to four environmental experts in the basic evaluation index set on iron stability.

\section{Weight analysis}

The effect of the four water quality factors on iron stability could be transformed into one comprehensive evaluation value (weight analysis) using the fuzzy comprehensive evaluation method, which provided a relatively simple approach for analyzing the water quality factors.

Weight was the relative concept for one indicator. The weight of indicator was the relative importance of the indicators in the overall evaluation. The weights of the four water quality factors under the influence of iron stability obtained blindness analysis and normalization 
Table 1 Application of two kinds of evaluation factor types in membership function

\begin{tabular}{|c|c|c|c|}
\hline Memberst & hip function & Incremental factor & Descending factor \\
\hline$\mu_{v_{1}}\left(u_{i}\right)=$ & $\left\{\begin{array}{l}0.5 \times\left[1+\frac{u_{i}-k_{1}}{k_{1}^{\prime}-k_{1}}\right] \\
0.5 \times\left[1-\frac{k_{1}-u_{i}}{k_{1}-k_{2}^{\prime}}\right]\end{array}\right.$ & $\mu_{v_{1}}\left(u_{i}\right)=\left\{\begin{array}{c}u_{i}<k_{1}^{\prime} \\
k_{1}^{\prime} \leq u_{i}<k_{1} \\
k_{1} \leq u_{i}<k_{2}^{\prime} \\
u_{i} \geq k_{2}^{\prime}\end{array}\right.$ & $\mu_{v_{1}}\left(u_{i}\right)=\left\{\begin{array}{c}u_{i} \geq k_{1}^{\prime} \\
k_{1}^{\prime}>u_{i} \geq k_{1} \\
k_{1}>u_{i} \geq k_{2}^{\prime} \\
u_{i}<k_{2}^{\prime}\end{array}\right.$ \\
\hline$\mu_{\nu_{2}}\left(u_{i}\right)=$ & $\begin{array}{r}0.5 \times\left[1-\frac{u_{i}-k_{1}}{k_{1}^{\prime}-k_{1}}\right] \\
0.5 \times\left[1+\frac{k_{1}-u_{i}}{k_{1}-k_{2}^{\prime}}\right] \\
0.5 \times\left[1+\frac{u_{i}-k_{2}}{k_{2}^{\prime}-k_{2}}\right] \\
0.5 \times\left[1-\frac{k_{2}-u_{i}}{k_{2}-k_{3}^{\prime}}\right] \\
0\end{array}$ & $\mu_{v_{2}}\left(u_{i}\right)=\left\{\begin{array}{c}u_{i}<k_{1}^{\prime} \\
k_{1}^{\prime} \leq u_{i}<k_{1} \\
k_{1} \leq u_{i}<k_{2}^{\prime} \\
k_{2}^{\prime} \leq u_{i}<k_{2} \\
k_{2} \leq u_{i}<k_{3}^{\prime} \\
u_{i} \geq k_{3}^{\prime}\end{array}\right.$ & $\mu_{v_{2}}\left(u_{i}\right)=\left\{\begin{array}{c}u_{i} \geq k_{1}^{\prime} \\
k_{1}^{\prime}>u_{i} \geq k_{1} \\
k_{1}>u_{i} \geq k_{2}^{\prime} \\
k_{2}^{\prime}>u_{i} \geq k_{2} \\
k_{2}>u_{i} \geq k_{3}^{\prime} \\
u_{i}<k_{3}^{\prime}\end{array}\right.$ \\
\hline$\mu_{v_{3}}\left(u_{i}\right)=$ & $\begin{array}{r}0.5 \times\left[1-\frac{u_{i}-k_{2}}{k_{2}^{\prime}-k_{2}}\right] \\
0.5 \times\left[1+\frac{u_{i}-k_{3}}{k_{3}^{\prime}-k_{3}}\right] \\
0.5 \times\left[1-\frac{k_{3}-u_{i}}{k_{3}-k_{4}^{\prime}}\right] \\
0\end{array}$ & $\mu_{v_{3}}\left(u_{i}\right)=\left\{\begin{array}{c}u_{i}<k_{2}^{\prime} \\
k_{2}^{\prime} \leq u_{i}<k_{2} \\
k_{2} \leq u_{i}<k_{3}^{\prime} \\
k_{3}^{\prime} \leq u_{i}<k_{3} \\
k_{3} \leq u_{i}<k_{4}^{\prime} \\
u_{i} \geq k_{4}^{\prime}\end{array}\right.$ & $\mu_{v_{3}}\left(u_{i}\right)=\left\{\begin{array}{c}u_{i} \geq k_{2}^{\prime} \\
k_{2}^{\prime}>u_{i} \geq k_{2} \\
k_{2}>u_{i} \geq k_{3}^{\prime} \\
k_{3}^{\prime}>u_{i} \geq k_{3} \\
k_{3}>u_{i} \geq k_{4}^{\prime} \\
u_{i}<k_{4}^{\prime}\end{array}\right.$ \\
\hline$\mu_{v_{4}}\left(u_{i}\right)=$ & $\left\{\begin{array}{r}0.5 \times\left[1-\frac{u_{i}-k_{3}}{k_{3}^{\prime}-k_{3}}\right] \\
0.5 \times\left[1+\frac{k_{3}-u_{i}}{k_{3}-k_{4}^{\prime}}\right] \\
0.5 \times\left[1+\frac{u_{i}-k_{4}}{k_{4}^{\prime}-k_{4}}\right] \\
0.5 \times\left[1-\frac{k_{4}-u_{i}}{k_{4}-k_{5}^{\prime}}\right]\end{array}\right.$ & $\mu_{v_{4}}\left(u_{i}\right)=\left\{\begin{array}{c}u_{i}<k_{3}^{\prime} \\
k_{3}^{\prime} \leq u_{i}<k_{3} \\
k_{3} \leq u_{i}<k_{4}^{\prime} \\
k_{4}^{\prime} \leq u_{i}<k_{4} \\
k_{4} \leq u_{i}<k_{5}^{\prime} \\
u_{i} \geq k_{5}^{\prime}\end{array}\right.$ & $\mu_{v_{4}}\left(u_{i}\right)=\left\{\begin{array}{c}u_{i} \geq k_{3}^{\prime} \\
k_{3}^{\prime}>u_{i} \geq k_{3} \\
k_{3}>u_{i} \geq k_{4}^{\prime} \\
k_{4}^{\prime}>u_{i} \geq k_{4} \\
k_{4}>u_{i} \geq k_{5}^{\prime} \\
u_{i}<k_{5}^{\prime}\end{array}\right.$ \\
\hline$\mu_{\nu_{5}}\left(u_{i}\right)=$ & $\left\{\begin{array}{r}0 \\
0.5 \times\left[1-\frac{u_{i}-k_{4}}{k_{4}^{\prime}-k_{4}}\right] \\
0.5 \times\left[1+\frac{k_{4}-u_{i}}{k_{4}-k_{5}^{\prime}}\right]\end{array}\right.$ & $\mu_{v_{5}}\left(u_{i}\right)=\left\{\begin{array}{c}u_{i}<k_{4}^{\prime} \\
k_{4}^{\prime} \leq u_{i}<k_{4} \\
k_{4} \leq u_{i}<k_{5}^{\prime} \\
u_{i} \geq k_{5}^{\prime}\end{array}\right.$ & $\mu_{v_{5}}\left(u_{i}\right)=\left\{\begin{array}{c}u_{i} \geq k_{4}^{\prime} \\
k_{4}^{\prime}>u_{i} \geq k_{4} \\
k_{4}>u_{i} \geq k_{5}^{\prime} \\
u_{i}<k_{5}^{\prime}\end{array}\right.$ \\
\hline
\end{tabular}

$k_{1}, k_{2}, k_{3}, k_{4}, k_{5}$ represented the critical value of the adjacent classification interval; $k_{r}^{\prime} k_{2}^{\prime} k_{3}^{\prime} k_{4}^{\prime}$ and $k_{5}^{\prime}$ were the midpoint of the rank of the corresponding level $v_{1}, v_{2}, v_{3}$ $v_{4}$, and $v_{5}$, respectively

Table 2 Optimized method of calculating membership

\begin{tabular}{lll}
\hline $\boldsymbol{K}_{\boldsymbol{n}}$ & Incremental factor & Descending factor \\
\hline$u_{i}<k_{1}^{\prime}$ & $Q_{i}=\frac{k_{1}^{\prime}-u_{i}}{V \max }$ & $Q_{i}=\frac{u_{i}-k_{1}^{\prime}}{V \max }$ \\
$u_{i}<k_{5}^{\prime}$ & $Q_{i}=\frac{u_{i}-k_{5}^{\prime}}{V \max }$ & $Q_{i}=\frac{k_{1}^{\prime}-u_{i}}{V \max }$ \\
\hline
\end{tabular}

analysis according to the results of the expert sorting. $W$ formula (18) represented the weight vector of the four water quality evaluation indicators could be calculated by formula (2) to formula (10): 
Table 3 The sorting table of the four water quality factors

\begin{tabular}{lllll}
\hline Case & Chloride & Sulfate & DOM & PH \\
\hline 1 & 4 & 3 & 1 & 2 \\
2 & 3 & 4 & 1 & 2 \\
3 & 4 & 2 & 1 & 3 \\
4 & 4 & 3 & 2 & 1
\end{tabular}

Table 4 Different water cases under four water quality factors

\begin{tabular}{lcccc}
\hline Condition & Chloride (mg/L) & Sulfate $(\mathbf{m g} / \mathbf{L})$ & DOC $(\mathbf{m g} / \mathbf{L})$ & $\mathbf{p H}$ \\
\hline 1 & 857.5 & 43.00 & 9.399 & 6.06 \\
2 & 1057 & 140.53 & 33.307 & 6.25 \\
3 & 1808.2 & 267.99 & 3.828 & 5.84 \\
4 & 159.2 & 132.69 & 5.348 & 6.85 \\
\hline \multicolumn{4}{l}{$\begin{array}{l}\text { The data of four water quality indicators are from the hollows located between } \\
\text { tubercles at the bottom of four different pipe fragments [23] }\end{array}$} \\
The content of DOM was characterized using DOC
\end{tabular}

$$
W=[0.1444,0.2521,0.3126,0.2909] .
$$

Although the basic evaluation indexes were different according to the different experts' order, the sorting of the weights on the iron stability could also be calculated after the process of expert order, blind analysis, and normalization. The sorting of the weights on the iron stability was $\mathrm{DOM}>\mathrm{pH}>$ sulfate $>$ chloride in this research, which was similar to the previous research [22].

\section{Results}

Different water quality has a good correlation with the stability of iron in the DWDSs. In the case study, four kinds of water factors about the steady water in the DWDSs were considered according to Swietlik et al. [23], which is used to explain the effects of water quality factors and iron stability. Four conditions of steady water were collected from the black water surrounding and partly filling the tubercles in the different parts of pipes [23]. The details of the water factors are shown in Table 4.

Table 5 Membership calculation (condition 1)

\begin{tabular}{lllllll}
\hline Water quality factor & Value & Slight risk $\left(\boldsymbol{v}_{\text {slr }}\right)$ & Small risk $\left(\boldsymbol{v}_{\text {smr }}\right)$ & General risk $\left(\boldsymbol{v}_{\text {ger }}\right)$ & $\begin{array}{l}\text { Greater risk } \\
\left(\boldsymbol{v}_{\text {grr }}\right)\end{array}$ & $\begin{array}{l}\text { Significant } \\
\text { risk }\left(\boldsymbol{v}_{\text {sir }}\right)\end{array}$ \\
\hline Chloride & $857.5 \mathrm{mg} / \mathrm{L}$ & 0 & 0 & 0 & 0 & 1 \\
Sulfate & $43.00 \mathrm{mg} / \mathrm{L}$ & 0.6400 & 0.3600 & 0 & 0 & 0 \\
DOC & $9.40 \mathrm{mg} / \mathrm{L}$ & 0 & 0.1500 & 0.8500 & 0 & 0 \\
pH & 6.06 & 0 & 0 & 0 & 0 & 1 \\
\hline
\end{tabular}

Table 6 Membership calculation (condition 2)

\begin{tabular}{|c|c|c|c|c|c|c|}
\hline Water quality factor & Value & $\begin{array}{l}\text { Slight risk } \\
\left(v_{\text {slr }}\right)\end{array}$ & $\begin{array}{l}\text { Small risk } \\
\left(v_{\text {smr }}\right)\end{array}$ & General risk $\left(v_{\text {ger }}\right)$ & Greater risk $\left(v_{\text {grr }}\right)$ & $\begin{array}{l}\text { Significant } \\
\text { risk }\left(v_{\text {sir }}\right)\end{array}$ \\
\hline Chloride & 1057 mg/L & 0 & 0 & 0 & 0 & 1 \\
\hline Sulfate & $140.53 \mathrm{mg} / \mathrm{L}$ & 0 & 0 & 0.6894 & 0.3106 & 0 \\
\hline DOC & $33.31 \mathrm{mg} / \mathrm{L}$ & 0 & 0 & 0 & 0 & 1 \\
\hline $\mathrm{pH}$ & 6.25 & 0 & 0 & 0 & 0 & 1 \\
\hline
\end{tabular}

Table 7 Membership calculation (condition 3)

\begin{tabular}{|c|c|c|c|c|c|c|}
\hline Water quality factor & Value & Slight risk $\left(v_{\text {slr }}\right)$ & Small risk $\left(v_{\text {smr }}\right)$ & $\begin{array}{l}\text { General risk } \\
\left(v_{\text {ger }}\right)\end{array}$ & $\begin{array}{l}\text { Greater risk } \\
\left(v_{\text {grr }}\right)\end{array}$ & $\begin{array}{l}\text { Significant } \\
\text { risk }\left(v_{\text {sir }}\right)\end{array}$ \\
\hline Chloride & $1808.2 \mathrm{mg} / \mathrm{L}$ & 0 & 0 & 0 & 0 & 1 \\
\hline Sulfate & $267.99 \mathrm{mg} / \mathrm{L}$ & 0 & 0 & 0 & 0 & 1 \\
\hline DOC & $3.83 \mathrm{mg} / \mathrm{L}$ & 0.5425 & 0.4575 & 0 & 0 & 0 \\
\hline $\mathrm{pH}$ & 5.84 & 0 & 0 & 0 & 0 & 1 \\
\hline
\end{tabular}


Table 8 Membership calculation (condition 4)

\begin{tabular}{lllllll}
\hline Water quality factor & Value & Slight risk $\left(\boldsymbol{v}_{\text {slr }}\right)$ & Small risk $\left(\boldsymbol{v}_{\text {smr }}\right)$ & General risk $\left(\boldsymbol{v}_{\text {ger }}\right)$ & Greater risk $\left(\boldsymbol{v}_{\text {grr }}\right)$ & $\begin{array}{l}\text { Significant } \\
\text { risk }\left(\boldsymbol{v}_{\text {sir }}\right)\end{array}$ \\
\hline Chloride & $159.2 \mathrm{mg} / \mathrm{L}$ & 0 & 0 & 0.3160 & 0.6840 & 0 \\
Sulfate & $132.69 \mathrm{mg} / \mathrm{L}$ & 0 & 0 & 0.8462 & 0.1538 & 0 \\
DOC & $5.35 \mathrm{mg} / \mathrm{L}$ & 0.1625 & 0.8375 & 0 & 0 & 0 \\
$\mathrm{pH}$ & 6.85 & 0 & 0 & 0.2000 & 0.8000 & 0 \\
\hline
\end{tabular}

Table 9 Water quality risk assessment

\begin{tabular}{llll}
\hline $\begin{array}{l}\text { Water } \\
\text { condition }\end{array}$ & Risk assessment & $\begin{array}{l}\text { The optimized } \\
\text { risk value }\end{array}$ & $\begin{array}{l}\text { Iron } \\
\text { concentration } \\
\text { [23] }\end{array}$ \\
\hline 1 & 3.4103 & 3.5826 & $360 \mathrm{mg} / \mathrm{L}$ \\
2 & 4.5741 & 4.8780 & $1120 \mathrm{mg} / \mathrm{L}$ \\
3 & 3.8926 & 4.5621 & $960 \mathrm{mg} / \mathrm{L}$ \\
4 & 3.0069 & 3.0069 & $0.4 \mathrm{mg} / \mathrm{L}$ \\
\hline
\end{tabular}

\section{Membership analysis}

The membership degree of the four water quality factors were calculated in five grades based on the calculation method of the membership function, as shown in Tables 5, 6, 7 8. The content of DOM was characterized using DOC. The specific membership was calculated according to the different values of the water quality factors according to Table 1 . In order to better evaluate the effect of water quality factors on iron stability, the weight coefficient of each index was given from 1 to 2, 3, 4, 5 which represented slight risk, small risk, general risk, greater risk, significant risk, respectively.

\section{Risk assessment}

Different water quality factors had different effects on the risk of iron stability. The risk value under the four water conditions could be calculated synthetically based on the membership value and the weight of the four water quality factors which showed in formula (12) and formula (13). The results of risk value and iron concentration in different conditions are shown in Table 9. The lower risk of iron stability appeared under the lower risk value; meanwhile, the greater risk of iron stability appeared under the higher value, respectively. 'Iron concentration' in Table 9 meant iron concentration in water which surrounding and partly filling the tubercles in the pipes in the four conditions. The concentrations of iron were $360 \mathrm{mg} / \mathrm{L}, 1120 \mathrm{mg} / \mathrm{L}, 960 \mathrm{mg} / \mathrm{L}$ and $0.4 \mathrm{mg} / \mathrm{L}$ in conditions 1 to 4 , which meant the iron risk could be described as the order of condition 4 , condition 1 , condition 3 , and condition 2 from low to high.

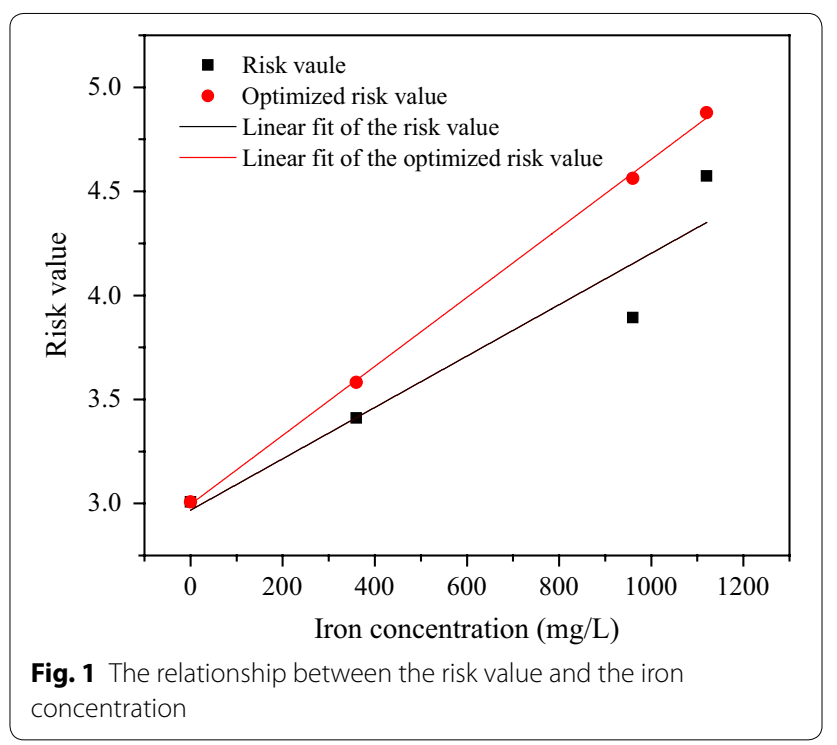

However, for the chloride and sulfate values in water quality conditions 1,2 and 3, they were all larger than the median value of the significant risk. Therefore, the comprehensive risk score cannot be correctly judged. In order to solve the problem of membership degree, it was necessary to use the optimized calculation method for calculation by formula (13). The calculated value is shown by "The optimized risk value" in Table 9. The comparison of the two calculation conditions is shown in Fig. 1, which was used to illustrate the relationship between the risk value and the iron concentration. Compared with the traditional fuzzy comprehensive evaluation method, the optimized method had a higher degree of fit which could more clearly prove the relationship between the risk value and the iron concentration. The analysis suggested that the $R^{2}$ values of the traditional method and the optimized method were 0.869 and 0.999 . Therefore, although the order of the risk was no different from before optimized, the revised risk values were significantly different from unrevised assessment, which coincided with the actual situation. 


\section{Discussion}

The phenomenon was consistent with the result obtained by the risk assessment in this research, which demonstrates that, (1) the selection of water quality factors for iron risk assessment in water supply pipelines is scientifically reasonable; (2) this risk assessment method can be used to judge the different water quality conditions for the iron stability of the pipeline influences. As the result, although different water quality factors had different effects on the stability of iron, the comprehensive evaluation of water quality could be evaluated by the risk assessment under the improved fuzzy comprehensive evaluation, which would be beneficial to the analysis of iron risk in water supply network.

\section{Conclusions}

Iron was an important index which would case turbidity, color and smell in water during the DWDSs. It was difficult to fully reflect iron concentration for the limited test points in the DWDSs. Different water quality factors had different influences on the iron stability. Therefore, the evaluation of the iron stability was complicated by the different of water quality parameters.

In this research, the optimized evaluation method was established to guide the iron stability under different water quality, especially under the condition that the values of water quality factors were out the median of the minimum/ maximum risk range. The article provided the view that the iron stability could be assessed by the combination of different water quality factors. Meanwhile, for the formulated relevant management strategies, the water supply enterprises could obtain the reasons of the iron risk increasing from the assessment, and adopt active management measures to reduce the risk of iron stability. In addition, this research was particularly useful for assessing the iron stability in the evaluation of water quality mutations.

\section{Abbreviations}

DOM: Dissolved organic matter; DWDSs: Drinking water distribution systems: DOC: Dissolved organic carbon; AHP: Analytic hierarchy process.

\section{Acknowledgements}

This work was jointly supported by the Water Pollution Control and Treatment Technology Major Project (2019YFC0408800, 2017ZX07201001) and the National Natural Science Foundation of China (51778452).

\section{Authors' contributions}

JW and HY were involved in the experiments and manuscript writing. JW and $\mathrm{HY}$ were responsible for the data analysis. KX and TT designed the study. TT contributed to correction of the manuscript. All authors read and approved the final manuscript.

\section{Funding}

The Water Pollution Control and Treatment Technology Major Project (2019YFC0408800, 2017ZX07201001) and the National Natural Science Foundation of China (51778452).

\section{Availability of data and materials}

The datasets obtained and analyzed in the current study are available from the corresponding author on reasonable request.

Ethics approval and consent to participate

Not applicable.

\section{Consent for publication}

Not applicable.

\section{Competing interests}

The authors declare that they have no competing interests.

\section{Author details}

${ }^{1}$ College of Environmental Science and Engineering, Tongji University, Shanghai 200092, China. ${ }^{2}$ Shanghai Institute of Pollution Control and Ecological Security, Shanghai 200092, China.

Received: 30 December 2019 Accepted: 11 May 2020

Published online: 24 May 2020

\section{References}

1. Sharma S, Kappelhof J, Groenendijk M, Schippers J (2001) Comparison of physicochemical iron removal mechanisms in filters. J Water Supply Res T 50(4):187-198. https://doi.org/10.2166/aqua.2001.0017

2. Sarin P, Snoeyink V, Bebee J, Jim K, Beckett M, Kriven W, Clement J (2004) Iron release from corroded iron pipes in drinking water distribution systems: effect of dissolved oxygen. Water Res 38(5):1259-1269. https:// doi.org/10.1016/j.watres.2003.11.022

3. Sarin P, Clement J, Snoeyink V, Kriven W (2003) Iron release from corroded unlined cast-iron pipe. J Am Water Works Ass 95(11):85-96. https://doi. org/10.1002/j.1551-8833.2003.tb10495.x

4. McNeill L, Edwards M (2001) Review of Iron pipe corrosion in distribution systems. Am Water Works Ass 93(7):88-98. https://doi. org/10.1002/j.1551-8833.2001.tb09246.X

5. Cui Y, Liu SM, Smith K, Yu KH, Hu HY, Jiang W, Li YH (2016) Characterization of corrosion scale formed on stainless steel delivery pipe for reclaimed water treatment. Water Res 88(1):816-825. https://doi.org/10.1016/j.watre s.2015.11.021

6. Li X, Wang H, Hu C, Yang M, Hu H, Niu J (2015) Characteristics of biofilms and iron corrosion scales with ground and surface waters in drinking water distribution systems. Corros Sci 90:331-339. https://doi. org/10.1016/j.corsci.2014.10.028

7. Edwards M, Triantafyllidou S (2007) Chloride-to-sulfate mass ratio and lead leaching to water. J Am Water Works Ass 99(7):96-109. https://doi. org/10.1002/j.1551-8833.2007.tb07984.x

8. Yang F, Shi B, Gu J, Wang D, Yang M (2012) Morphological and physicochemical characteristics of iron corrosion scales formed under different water source histories in a drinking water distribution system. Water Res 46(16):5423-5433. https://doi.org/10.1016/j.watres.2012.07.031

9. Rahman M, Gagnon G (2013) Bench scale evaluation of Fe(II) ions on haloacetic acids (HAAs) formation in synthetic water. J Water Supply Res $T$ 62(3):155-168. https://doi.org/10.2166/aqua.2013.116

10. Liu C, Gunten U, Croue J (2013) Chlorination of bromide-containing waters: Enhanced bromate formation in the presence of synthetic metal oxides and deposits formed in drinking water distribution systems. Water Res 47(14):5307-5315. https://doi.org/10.1016/j.watres.2013.06.010

11. Fabbricino $M$, Korshin $G$ (2014) Changes of the corrosion potential of iron in stagnation and flow conditions and their relationship with metal release. Water Res 62:136-146. https://doi.org/10.1016/j.watre S.2014.05.053

12. Hao R, Liu F, Ren H, Cheng S (2013) Study on a comprehensive evaluation method for the assessment of the operational efficiency of wastewater treatment plants. Stoch Env Res Risk A 27(3):747-756. https://doi. org/10.1007/s00477-012-0637-2

13. Guan X, Liang S, Meng Y (2016) Evaluation of water resources comprehensive utilization efficiency in the Yellow River Basin. Water Sci Tech-W Sup 16(6):1561-1570. https://doi.org/10.2166/ws.2016.057 
14. Han L, Song Y, Duan L, Yuan P (2015) Risk assessment methodology for Shenyang Chemical Industrial Park based on fuzzy comprehensive evaluation. Environ Earth Sci 73(9):5185-5192. https://doi.org/10.1007/s1266 5-015-4324-8

15. Gong L, Jin C (2009) Fuzzy Comprehensive Evaluation for Carrying CapaC ity of Regional Water Resources. Water Resour Manag 23(12):2505-2513. https://doi.org/10.1007/s11269-008-9393-y

16. Islam N, Rodriguez M, Farahat A, Sadiq R (2017) Minimizing the impacts of contaminant intrusion in small water distribution networks through booster chlorination optimization. Stoch Env Res Risk A 31(7):1759-1775. https://doi.org/10.1007/s00477-017-1440-x

17. Simpson M, Allen D, Journeay M (2014) Assessing risk to groundwater quality using an integrated risk framework. Environ Earth Sci 71(11):49394956. https://doi.org/10.1007/s12665-013-2886-X

18. Wang Y, Jing H, Han L, Yu L, Zhang Q (2014) Risk analysis on swell-shrink capacity of expansive soils with efficacy coefficient method and entropy coefficient method. Appl Clay Sci 99:275-281. https://doi.org/10.1016/j. clay.2014.07.005

19. Quaranta G, Kunnath S, Sukumar N (2014) Maximum-entropy meshfree method for nonlinear static analysis of planar reinforced concrete structures. Eng Struct 60:179-189. https://doi.org/10.1016/j.engst ruct.2013.12.011
20. Ye J (2011) Fuzzy cross entropy of interval-valued intuitionistic fuzzy sets and its optimal decision-making method based on the weights of alternatives. Expert Syst Appl 38(5):6179-6183. https://doi.org/10.1016/j. eswa.2010.11.052

21. Lasheen M, Sharaby C, El-Kholy N, Elsherif I, Ei-Wakeel S (2008) Factors influencing lead and iron release from some Egyptian drinking water pipes. J Hazard Mater 160(2-3):675-680. https://doi.org/10.1016/j.jhazm at.2008.03.040

22. Wang J, Yan H, Xin K, Tao T (2019) Iron stability on the inner wall of prepared polyethylene drinking pipe: effects of multi-water quality factors. Sci Total Environ 658:1006-1012. https://doi.org/10.1016/j.scito tenv.2018.12.127

23. Swietlik J, Raczyk-Stanislawiak U, Piszora P, Nawrocki J (2012) Corrosion in drinking water pipes: the importance of green rusts. Water Res 46(1):1-10. https://doi.org/10.1016/j.watres.2011.10.006

\section{Publisher's Note}

Springer Nature remains neutral with regard to jurisdictional claims in published maps and institutional affiliations.

\section{Submit your manuscript to a SpringerOpen ${ }^{\circ}$ journal and benefit from:}

- Convenient online submission

- Rigorous peer review

- Open access: articles freely available online

- High visibility within the field

- Retaining the copyright to your article

Submit your next manuscript at $\boldsymbol{\nabla}$ springeropen.com 